\title{
EDITORIAL
}

\section{ALGUNOS COMENTARIOS SOBRE LA LEY 1751 DEL 2015 QUE REGULA EL DERECHO FUNDAMENTAL A LA SALUD}

\author{
Jorge Enrique Pérez Cardenas ${ }^{1}$ \\ Director Revista Biosalud \\ Departamento de Ciencias Básicas \\ Facultad de Ciencias para la Salud \\ Universidad de Caldas
}

En lo que va transcurrido del año, ha habido mucha publicidad por la aplicación de la ley 1751 del 2015 relacionada con definir o confirmar los derechos y deberes de la población que vive en Colombia, en lo relacionado con los servicios de salud.

Las noticias relacionadas con la aplicación de esta ley solamente han resaltado la importancia de como por medio de la misma se ha acabado el plan obligatorio de salud que regía antiguamente en Colombia; sin embargo, como ley estatutaria, es un conjunto de directrices y normas que establece los derechos y deberes no solo de los usuarios de este sistema, sino también de los agentes prestadores con el fin de acabar con una serie de inequidades y seguramente del uso del mecanismo de la tutela para exigir el cumplimiento del sagrado derecho constitucional de acceso a una prestación digna y oportuna de los servicios de salud de los colombianos.

A pesar de la promulgación de esta ley, en algunas EPS se siguen presentando problemas para el acatamiento de la misma al someter a sus afiliados a dilaciones en la prestación de los servicios a pesar de que en el contenido de la misma se define que el derecho a la salud se debe obtener de manera "oportuna y eficaz". Es claro que los entes territoriales de salud, mediante sus inspecciones periódicas, están al tanto de las quejas y reclamos por la mala prestación de atención a los usuarios, y por lo tanto, este último recurso debe ser el utilizado por las personas para enterar al gobierno del incumplimiento por parte de las EPS.

En el artículo 6 de esta ley se establece el principio de la aceptabilidad en el cual se menciona que en la aplicación de los servicios de salud se debe, respetar "las particularidades socioculturales y la cosmovisión de la salud de los usuarios de este sistema"; este principio plantea un problema con algunas comunidades como la indígena, que no aceptan la medicina occidental para el tratamiento de sus dolencias; lo cual implicaría además que el sistema de salud debería tener personas para la atención personalizada de estos individuos, que les garanticen la prestación de la salud de acuerdo con sus normas y principios. Pero otro problema adicional es que en esta ley se prohíbe el uso de procedimientos y medicamentos no validados científicamente que demuestren su eficacia en el tratamiento de alguna patología; esta prohibición ya sería un argumento para la negación de los servicios de salud a aquellas personas que no aceptan los procedimientos científicamente validados a menos que el mismo paciente, a pesar de sus principios, renuncie a los mismos y acepte las indicaciones médicas prescritas para diagnosticar y atender las patologías que lo aquejan.

\footnotetext{
${ }^{1}$ Profesor, Departamento de Ciencias Básicas. Facultad de Ciencias para la Salud. Universidad de Caldas
} 
Por otro lado, considerando que aquellas comunidades que no están de acuerdo con la medicina que actualmente se aplica en el país, tienen la oportunidad de participar en las decisiones tomadas por el Estado relacionadas con los servicios de salud, podrían solicitar al mismo la generación de mecanismos que propendan la validación de los procedimientos de su medicina para que sean tenidos en cuenta dentro del sistema. Esto implicaría el uso de diferentes métodos de investigación que contribuyan a darle validez científica a los mismos.

Dentro de los principios del derecho fundamental a la salud se enuncia el de accesibilidad. En este principio se determina que al sistema deba ser accesible para todos; esto implica el de tener servicios de salud hasta en las zonas más apartadas del país; las implicaciones de este principio tocan a otros entes del Estado ya que se requeriría para ello, en razón de la oportunidad de los servicios, buenas vías de acceso, la presencia de prestadores de salud en sitios estratégicos de Colombia, y lo que es más importante, la garantía de que todos los pobladores del país de verdad tienen el derecho a la prestación del servicio, mediante la afiliación de las personas al régimen contributivo o subsidiado. Este solo hecho podría permitir que iniciativas privadas llegaran a estos sitios apartados ya que se les estaría garantizando el pago de sus servicios por parte de las EPS o ARS que tienen afiliados a dichos usuarios. El gobierno debe entonces utilizar mecanismos más activos que permitan el acceso a los servicios de salud de todos los habitantes del país ya que según esta ley, la misma no solo aplica a los que tienen la nacionalidad sino también para aquellos que no la tienen, de acuerdo al principio de universalidad adoptado en esta ley.

Es un hecho que los programas de prevención de la enfermedad y de promoción de la salud son una parte importante del sistema, ya que de esta manera se evitan sobrecargas en el mismo por enfermedades que se podrían haber prevenido. La preservación de la salud es un deber de todos los actores del sistema de acuerdo con esta ley; sin embargo, los mecanismos efectivos para el logro de este importante objetivo son muy incipientes en nuestro medio; puedo estar equivocado, pero no conozco, al menos en mi EPS, las estrategias de promoción y prevención que de manera activa incidan en cada uno de sus afiliados. El Estado debería normatizar este aspecto para que las EPS y ARS no sigan aplicando pañitos de agua tibia, sino que de verdad entren en esta estrategia que traería muchos beneficios al país.

Por último, hay dos aspectos finales que me parecen bastante importantes. El primero es la definición de que en la prestación de los servicios de salud debe prevalecer la rentabilidad social y no la económica. Este aspecto implica que el estado debe garantizar la supervivencia de las EPS y ARS privadas; pero además, también debe vigilar estrechamente a las mismas para evitar el lucramiento de los promotores de estas iniciativas, tal como ha ocurrido anteriormente. Si el Estado aplicara con rigurosidad esta vigilancia, me pregunto: ¿cuántas de las EPS que actualmente tenemos en Colombia permanecerían?

El segundo aspecto final se refiere a las prebendas dadas por algunos prestadores al personal médico en desmedro de su actuación profesional y ética. La ley garantiza la autonomía profesional relacionada con el diagnóstico y tratamiento de los pacientes, aspecto que a veces es limitado por las directivas de las empresas prestadoras y que seguirá siendo limitado mientras existan las condiciones de contratación que no garantizan una estabilidad laboral de los profesionales de la salud, pauperizando su ejercicio profesional de acuerdo con aquellos lineamientos soterrados dados por los entes que los contratan, dentro de los que se cuentan no solo prestadores privados, sino también públicos, que son los que deberían dar ejemplo en la aplicación de esta ley. 